\title{
KEBUTUHAN ENERGI PADA PEMBUATAN PAPAN PARTIKEL DARI TANDAN KOSONG KELAPA SAWIT, SERBUK KULIT PINUS DAN AKASIA
}

\author{
Sulaiman $^{1}$,Thomas Tegar $^{2}$ \\ Dosen Jurusan Teknik Mesin Institut Teknologi Padang ${ }^{1}$, Mahasiswa Jurusan Teknik Mesin Institut \\ Teknologi Padang ${ }^{2}$ \\ thomasenju@gmail.com² \\ DOI: http://dx.doi.org/10.31869/rtj.v2i2.1434
}

\begin{abstract}
Human needs for wood as building materials or furniture continue to increase along with the increase in population, while the availability of wood in the forest is both limited in number and quality. This affects the particle board industry which is increasingly difficult to get good quality solid wood. One alternative to replace wood particles is Oil Palm Empty Bunches which has enormous potential to be used in the engineering field, especially as raw material for making particle boards, by utilizing acacia bark as an adhesive (matrix). To make particle board energy is needed in the manufacturing process. The energy needed in the process of making particle boards is 47,446,211.61 Joules for 25 particle boards or for 1 board for 1,897,848.46 Joules. If converted to Rupiah, the value of one particle board is Rp. 5030. When compared with factory-made prices with a size of $120 \mathrm{~cm} x$ $250 \mathrm{~cm}$ with a thickness of $1.2 \mathrm{~cm}$ at a price of Rp. 90,000, the particle boards that have been made are more expensive than factory-made ones.
\end{abstract}

Key words : particle board, oil palm empty bunches, acacia powder, pine powder, energy consumption, particle board manufacture.

\section{PENDAHULUAN}

Kebutuhan manusia terhadap kayu sebagai bahan bangunan atau furnitur terus meningkat, seiring dengan meningkatnya pertambahan penduduk sementara ketersediaan kayu di hutan baik jumlah maupun kualitasnya semakin terbatas. Hal ini berpengaruh terhadap industry papanp artikel yang semakin sulit mendapatkan kayu yang solid dan berkualitas baik. Salah satu alternative menggantikan partikel kayu adalah Tandan Kosong Kelapa Sawit (TKKS). TKKS merupakan salah satu limbah hasil perkebunan yang ketersediaannya berlimpah dan belum optimal dimanfaatkan. Uraian di atas menunjukan bahwa TKKS memiliki potensi yang sangat besar untuk digunakan di bidang rekayasa, khususnya sebagai bahan baku pada pembuatan papan partikel, dengan memanfaatkan kulit kayu akasia dan pinuss ebagai perekat (matriks).Papan partikel umumnya berbentuk datar dengan ukuran relative panjang, lebar, dan tipis sehinggadisebut panel. Salah satu faktor yang dapat dilihat serta dianalisa adalah seberapa besar energi yang terpakai dalam pembuatan/pencetakan papan partikel. Oleh karena itu penulis akan menghitung dan menganalisa seberapa besar pemakaian energi yang terpakai pada pembuatan papan partikel dengan variasi suhu dan waktu yang bervariasi.

\section{LANDASAN TEORI}

\section{Energi}

Energi adalah kemampuan untuk melakukan usaha (kerja) atau melakukan suatu perubahan. Energi merupakan bagian dari suatu benda tetapi tidak terikat pada benda tersebut. Energi tidak dapat diciptakan atau dimusnahkan, tetapu dapat dirubah bentuknya. Energi juga disebut tenaga. Satuan energi menurut Satuan Internasional (SI) adalah joule (J). Sedangkan satuan energi lain yaitu erg, kalori, dan kWh. Energi bersifat fleksibel, artinya dapat berpindah dan berubah.

Berikut dijelaskan beberapa pengertian energi menurut para ahli. Menurut Arif Alfatah dan Muji Lestari, energi adalah sesuatu yang dibutuhkan oleh benda agar benda dapat melakukan usaha. Sedangkan Campbell, Reece dan Mitchell berpendapat bahwa pengertian energi adalahkemampuan untuk mengatur ulang suatu materi.

Jenis - jenis energi :

\section{Energi Kinetik}

Energi Kinetik adalah energi gerak, energi yang dimiliki benda atau objek karena geraknya. Energi kinetik berasal dari kata Yunani kinetikos yang artinya bergerak. 
Jadi, kamu pasti tahu kan kalau setiap benda yang bergerak maka benda tersebut memiliki energi kinetik.

Rumus Energi Kinetik dinotasikan dengan :

$$
E K=\frac{1}{2} \boldsymbol{m} v^{2}
$$

Dimana :

$$
\begin{aligned}
& \mathrm{EK}=\text { EnergiKinetikbenda (Joule) } \\
& \mathrm{m}=\text { massabenda }(\mathrm{kg}) \\
& \mathrm{v}=\operatorname{kecepatanbenda}\left(\mathrm{m} / \mathrm{s}^{2}\right)
\end{aligned}
$$

Usaha merupakan besarnya energi. Pada konteks ini, usaha merupakan perubahan energi. Hubungan usaha dengan Energi Kinetik dinotasikan dengan:

$$
W=\Delta E K=\frac{1}{2} m\left(v_{2}^{2}-v_{1}^{2}\right)
$$

Dimana:

$$
\mathrm{W} \quad=\text { Usaha yang dilakukan }
$$

benda (Joule)

(Joule)

$$
\text { EK = perubahan Energi Kinetik }
$$

$$
v_{2}^{2}-v_{1}^{2}=\text { perubahan kecepatan }\left(\mathrm{m} / \mathrm{s}^{2}\right)
$$

\section{Energi Potensial}

Saat benda bergerak, dapat dikatakan benda memiliki energi kinetik. Akan tetapi, benda juga kemungkinan memiliki Energi Potensial. Energi Potensial adalah energi yang dimiliki benda karena posisinya atau bentuk maupun susunannya. Salah satu contoh energi potensial adalah energi potensial gravitasi atau selanjutnya kita sebut Energi Potensial. Energi Potensial disebabkan adanya gaya gravitasi. Suatu benda memiliki energi potensial yang besar jika massanya semakin besar dan ketinggiannya semakin tinggi.

Rumus Energi Potensial dinotasikan dengan :

$$
E P=m g h(\text { Joule })
$$

Dimana :

$$
\mathrm{EP}=\text { Energi Potensial benda (Joule) }
$$

$\mathrm{g}=$ kecepatan gravitasi $\left(9,8 \mathrm{~m} / \mathrm{s}^{2}\right)$

$\mathrm{h}=$ ketinggian benda $(\mathrm{m})$

Hubungan usaha dengan Energi

Potensial dinotasikan dengan :

$$
W=\Delta E P=m g\left(h_{2}-h_{1}\right)
$$

Dimana :

$$
h_{2}-h_{1}=\text { perubahan ketinggian (m) }
$$

\section{Energi Mekanik}

Energi Mekanik merupakan bentuk energi yang berkaitan dengan gerak. Nah, kedua tipe energi diatas yakni Energi Kinetik dan Energi Potensial merupakan bagian dari
Energi Mekanik.Persamaan Energi Mekanik dinotasikan dengan :

$$
E M=E K+E P
$$

\section{Usaha}

Usaha

adalahbesarnyaenergiuntukmerubahposisi yang diberikangayapadabendaatauobjek. Usaha yang dilakukansuatuobjekdidefinisikansebagaiperkal ianantarajarak yang ditempuhdengangaya yang searahdenganperpindahannya.

Usaha dinotasikan dengan $\mathrm{W}$ ang merupakan singkatan bahasa Inggris dari Work yang berarti kerja. Satuanusahaadalah Joule yang didefinisikansebagaibesarnyaenergi yang dibutuhkanuntukmemberigayasebesarsatu Newton sejauhsatu meter. Olehsebabitu, 1 Joule samadengan 1 Newton meter (N.m).

Rumus Usaha dinotasikan dengan :

$$
\boldsymbol{W}=\boldsymbol{F} \boldsymbol{x} \boldsymbol{X}
$$

Dimana :

$$
\begin{aligned}
& \mathrm{W}=\text { Usaha (Joule) } \\
& \mathrm{F}=\text { Gaya (Newton) } \\
& \mathrm{X}=\text { Jarak (Meter) }
\end{aligned}
$$

Jika gaya yang diberikan pada objek membentuk sudut maka persamaannya menjadi:

$$
W=F x \cos \theta x s
$$

Dimana :

$$
\begin{aligned}
& \mathrm{W}=\text { Usaha (Joule) } \\
& \mathrm{F}=\text { Gaya (Newton) } \\
& \Theta=\text { Sudut yang dibentuk gaya terhadap }
\end{aligned}
$$
perpindahan

Nilai usaha dapat berupa positif atau negatif tergantung arah gaya terhadap perpindahannya. Jika gaya yang diberikan pada objek berlawanan arah dengan perpindahannya, maka usaha yang diberikan bernilai negatif. Jika gaya yang diberikan searah dengan perpindahan, maka objek tersebut melakukan usaha positif.

Usaha juga dapat bernilai nol (0) atau objek tidak melakukan usaha jika :

- Diberikan gaya namun tidak terjadi perpindahan.

- Gaya yang diberikan tegak lurus dengan perpindahan $\left(\cos 90^{\circ}=0\right)$

\section{Daya}

Daya adalah laju energi yang dihantarkan selama melakukan usaha dalam periode waktu tertentu. Satuan SI (Satuan International) untuk 
Daya adalah joule/sekon $(\mathrm{J} / \mathrm{s})=$ Watt $(\mathrm{W})$. Satuan Watt digunakan untuk penghormatan kepada seorang ilmuan penemu mesin uap yang bernama James Watt. Satuan daya lainnya yang sering digunakan adalah Daya Kuda atau Horse Power (hp). $1 \mathrm{hp}=746$ Watt. Daya merupakan besaran skalar, karena Daya hanya memiliki nilai dan tidak memiliki arah.

DalamFisika, Daya disimbolkan dengan Persamaan Berikut :

$$
P=W / t
$$

Dimana :

$$
\begin{aligned}
& \mathrm{P}=\text { Daya }(\text { Watt) } \\
& \mathrm{W}=\text { Usaha (Joule) } \\
& \mathrm{t}=\text { Waktu (sekon) }
\end{aligned}
$$

Dari Persamaan diatas maka kita juga dapat mengubah rumus daya menjadi :

$$
\begin{aligned}
& P=(F . s) / t \\
& P=F . v
\end{aligned}
$$

Hasil tersebut didapatkan karena Rumus Usaha (W) = Gaya (F) dikaliJarak (s) dibagiWaktu (t)

Dan RumusKecepata(v) = jarak (s) dibagi waktu (t)

Keterangan :

$$
\begin{aligned}
& \mathrm{P}=\text { Daya }(\mathrm{J} / \mathrm{s} ; \text { Watt }) \\
& \mathrm{W}=\text { Usaha (Joule) } \\
& \mathrm{t}=\text { Waktu(sekon) } \\
& \mathrm{F}=\text { Gaya (Newton) } \\
& \mathrm{s}=\mathrm{Jarak}(\text { meter) } \\
& \mathrm{v}=\operatorname{Kecepatan}(\mathrm{m} / \mathrm{s})
\end{aligned}
$$

\section{METODOLOGI}

\section{Waktu dan Tempat}

Penelitian dilaksanakan di Laboratorium Teknik Mesin Institut Teknologi Padang untuk pembuatan papan dan pengamatan.

Penelitian dilaksanakan \pm 7 bulan dari pengumpulan bahan sampai proses pembuatan papan partikel.

Bahan utama yang digunakan pada pembuatan papan partikel ini adalah limbah tandan kosong kelapa sawit (TKKS), kulit pinus dan akasia.

Limbah tandan kosong kelapa sawit bersihkan terlebih dahulu kemudia dikukus dengan tambahan $\mathrm{NaOH}$ dengan tujuan mengeluarkan minyak yang ada pada serat tandan kosong kelapa sawit. Selanjutnya serat dicuci untuk membersihkannya dari minyak yang tertinggal. Setelah itu serat dikeringkan dan selanjutnya dipotong dan diayak dengan mesh ukuran 16.
Untuk pengolahan kulit pinus dan akasia, kulit pinus dan akasia dipotong menjadi kecil kemudian ditumbuk hingga halus kemudian di ayak menggunakan mesh 50 .

ProsedurPenelitian penelitian dilakukan dengan beberapa tahap, yaitu :

\section{PenyiapanSerat}

1. PengambilanTandan Kosong Kelapa Sawit (TKKS) di pabrik. Pengambilan serat Tandan Kosong Kelapa Sawit (TKKS) melalui observasi langsung kelapangan, berikut adalah gambar proses pengambilan serat untuk penelitian.

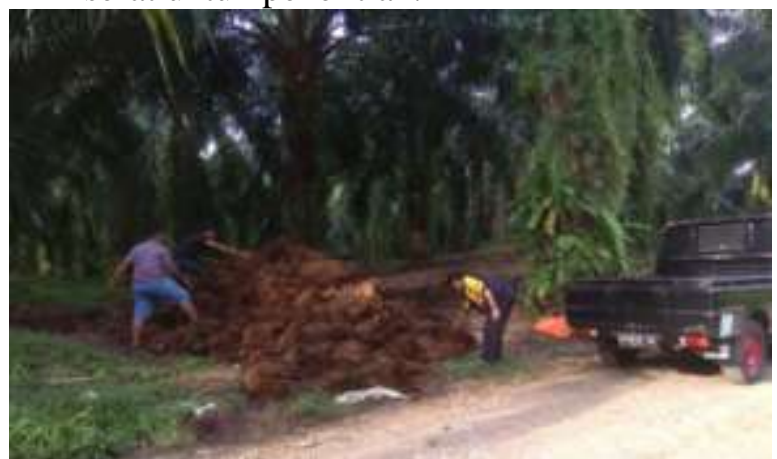

Gambar1 Pengambilan TKKS

2. Penguraian Serat TKKS

Proses penguraian dilakukan agar serat TKKS mudah untuk di keringkan dan dilakukan proses pemotongan. Proses pengeringanserat pada gambar di lakukandengan cara penjemuran dengan panas matahari.

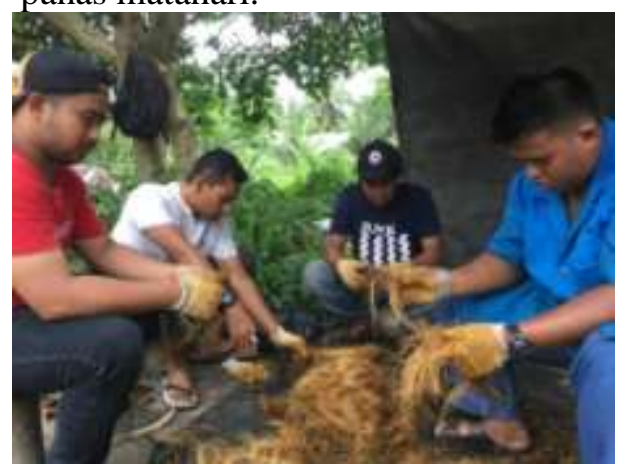

Gambar2Penguraian Serat TKKS

3. Pengeringan Serat TKKS

Proses pengeringan serat pada gambar di lakukan dengan cara penjemuran dengan panas matahari. 


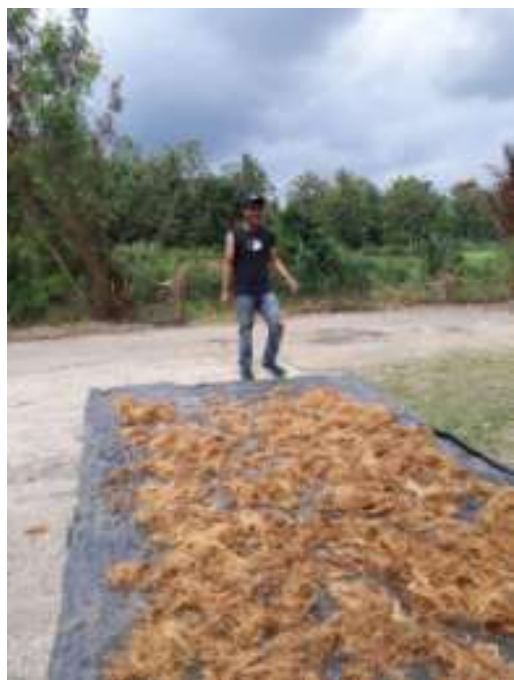

Gambar 3Pengeringan Serat TKKS

4. Pemotongan Serat

Setelah dirasa cukup kering kemudian serat diurai dan selanjutnya di potong menggunakan pisau dengan panjang serat setiap sampel yaitu0.1- $0,20 \mathrm{~mm}$

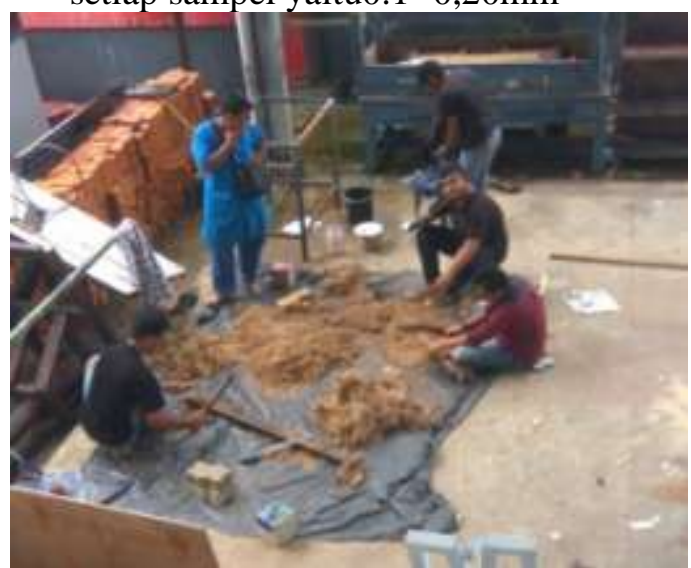

Gambar 4 PemotonganSerat TKKS

Penyiapan Serbuk Kulit Pohon Pinus dan Akasia

Campuran yang di gunakan adalah serbuk kulit pohon pinus dan akasialolos mesh 50 yang di ambil dari pohon pinus yang berada di Dekat Pantai Padang, setelah di ambil kulitnya lalu di jemur sampai benar benar kering, setelah itu di haluskan dengan cara di tumbuk dan di blender, hasil dari penghalusan kemudian di saring menggunakan saringan.

\section{PembuatanSampel}

Langkah -langkah dalam pembuatan papan serat sebagai berikut :

1. Menyiapkan bahan campuran komposit

Di dalam penelitian ini menggunakan komposisi antara serat TKKS dan serbuk kulit pinus dengan komposisi di sesuaikan dengan sampel yang ingin dibuat berukuran pada temperature yang bervariasi.

2. Mencampurkan serat TKKS dengan serbuk kulit pohon pinus dan akasia untuk selanjutnya di masukan kedalam cetakan dan di beri penekanan ( press ) menggunakan mesin press yang ada di labor Institut Teknologi Padang.

Pengamatan dan Perhitungan Energi yang Dibutuhkan

Salah satu faktor yang dapat dilihat serta dianalisa adalah seberapa besar energi yang terpakai dalam proses pembuatan papan partikel sampai selesai dicetak.

\section{DATA DAN PEMBAHASAN \\ Data}

1. Proses Pengolahan TKKS

\begin{tabular}{|c|c|}
\hline Proses & Parameter \\
\hline $\begin{array}{l}\text { Pengukusanserat } \\
\text { TKKS }\end{array}$ & $\begin{array}{l}\text { Waktupengukusan } \\
=240 \text { menit } \\
\text { Beratserat TKKS } \\
=35 \mathrm{~kg} \\
\text { Volume air }=60 \\
\text { liter }\end{array}$ \\
\hline $\begin{array}{l}\text { Pencucianserat } \\
\text { TKKS }\end{array}$ & $\begin{array}{l}\text { Waktupencucian = } \\
10 \text { menit } \\
\text { Beratserat yang } \\
\text { dicuci }=35 \mathrm{~kg}\end{array}$ \\
\hline $\begin{array}{l}\text { Pemotonganserat } \\
\text { TKKS }\end{array}$ & $\begin{array}{l}\text { Waktupemotongan } \\
=720 \text { menit } \\
\text { Beratserat }=35 \mathrm{~kg}\end{array}$ \\
\hline $\begin{array}{l}\text { Pengayakanserat } \\
\text { TKKS }\end{array}$ & $\begin{array}{l}\text { Waktupengayakan } \\
=750 \text { menit } \\
\text { Hasilayakan = } 25 \\
\mathrm{~kg}\end{array}$ \\
\hline
\end{tabular}

Tabel 1 Data PengolahanSerat TKKS

2. Proses PengolahanKulitPinusdanAkasia

\begin{tabular}{|c|c|}
\hline Proses & Parameter \\
\hline \multirow{3}{*}{$\begin{array}{l}\text { Pemotongankulit } \\
\text { a. Pinus }\end{array}$} & \\
\hline & Waktupemotongan \\
\hline & $=180$ menit \\
\hline \multirow{3}{*}{ b. Akasia } & Hasil = $7 \mathrm{~kg}$ \\
\hline & $\begin{array}{l}\text { Waktupemotongan } \\
=180 \text { menit }\end{array}$ \\
\hline & Hasil = $7 \mathrm{~kg}$ \\
\hline & \\
\hline & \\
\hline
\end{tabular}

$300 \quad$ Fakultas Teknik UMSB

ISSN 2599-2081

EISSN 2599-2090 


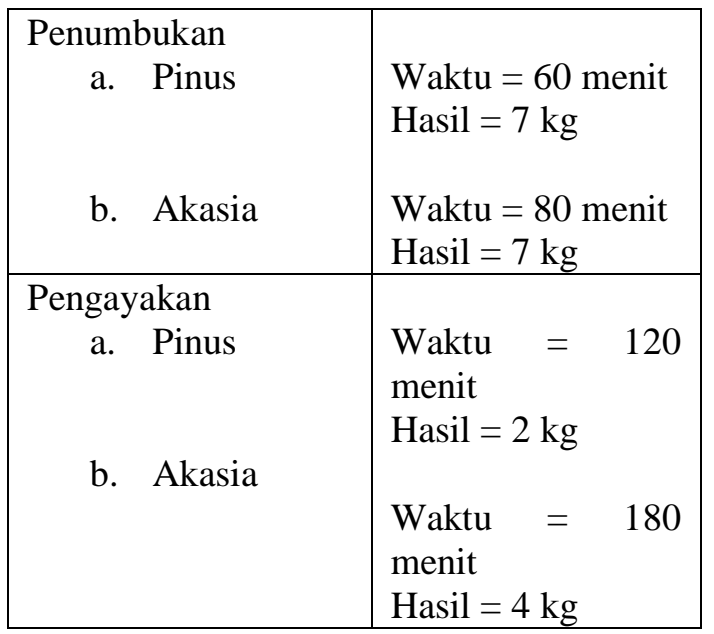

Tabel 2 Data PengolahanKulitPinusdanAkasia

\section{Prose Pencetakan}

\begin{tabular}{|c|c|}
\hline Proses & Parameter \\
\hline $\begin{array}{l}\text { Pengadukan bahan } \\
\text { (1 papan p qrtikel) }\end{array}$ & $\begin{array}{l}\text { Waktu }=10 \\
\text { menit } \\
\text { Daya motor }= \\
500 \text { watt } \\
\text { Hasil }=0,99 \mathrm{~kg}\end{array}$ \\
\hline $\begin{array}{l}\text { Kempa dingin } \\
\text { Komposisi : } \\
\text { a. } 70 / 30 \\
\text { b. } 75 / 25 \\
\text { c. } 80 / 20\end{array}$ & $\begin{array}{l}\text { Tekanan = 95 } \\
\mathrm{kg} / \mathrm{cm}^{2} \\
\text { Waktu }=5 \\
\text { menit } \\
\text { Tekanan = } 115 \\
\mathrm{~kg} / \mathrm{cm}^{2} \\
\text { Waktu }=5 \\
\text { menit } \\
\text { Tekanan = } 125 \\
\mathrm{~kg} / \mathrm{cm}^{2} \\
\text { Waktu }=5 \\
\text { menit } \\
\text { Tekanan = } \\
\mathrm{kg} / \mathrm{cm}^{2} \\
\text { Waktu }=5 \\
\text { menit } \\
\text { Tekanan }=170 \\
\text { kg/cm } \\
\text { Waktu } \\
\text { menit }\end{array}$ \\
\hline $\begin{array}{l}\text { Kempa Panas } \\
\text { Komposisi : } \\
\text { a. } \quad 70 / 30\end{array}$ & $\begin{array}{l}\text { Tekanan : } 95 \\
\mathrm{~kg} / \mathrm{cm}^{2}\end{array}$ \\
\hline
\end{tabular}



Tabel 3 Data PencetakanPapanPartikel

\begin{tabular}{|c|c|c|}
\hline \multicolumn{3}{|l|}{ Pembahasan } \\
\hline Proses & Energi (Joule) & $\begin{array}{c}\text { Rupiah } \\
\text { (Rp) }\end{array}$ \\
\hline $\begin{array}{c}\text { Pengukusan } \\
\text { Serat }\end{array}$ & 18.900 .000 & 7.765 \\
\hline $\begin{array}{l}\text { Pencucian } \\
\text { Serat }\end{array}$ & 61.803 & 25 \\
\hline $\begin{array}{l}\text { Pemotongan } \\
\text { Serat }\end{array}$ & $10.484,64$ & 4 \\
\hline $\begin{array}{c}\text { Pengayakan } \\
\text { Serat }\end{array}$ & 463.365 & 189 \\
\hline $\begin{array}{l}\text { Pemotongan } \\
\text { Kulit Pinus }\end{array}$ & 10.800 & 5 \\
\hline $\begin{array}{l}\text { Pemotongan } \\
\text { Kulit Akasia }\end{array}$ & 10.800 & 5 \\
\hline $\begin{array}{c}\text { Penumbukan } \\
\text { Kulit Pinus }\end{array}$ & $14.126,4$ & 6 \\
\hline $\begin{array}{l}\text { Penumbukan } \\
\text { Kulit Akasia }\end{array}$ & $18.835,2$ & 8 \\
\hline $\begin{array}{l}\text { Pengayakan } \\
\text { Serbuk Kulit }\end{array}$ & 92.673 & 38 \\
\hline
\end{tabular}


Vol. 2 No.2 Juni 2019

http://jurnal.umsb.ac.id/index.php/RANGTEKNIKJOURNAL

\begin{tabular}{|c|c|c|}
\hline Pinus & 119.151 & 49 \\
\hline $\begin{array}{c}\text { Pengayakan } \\
\text { Serbuk Kulit } \\
\text { Akasia }\end{array}$ & $\begin{array}{c}2.075(25 \\
\text { papan) }\end{array}$ & 3.044 \\
\hline $\begin{array}{c}\text { Pengadukan } \\
\text { Bahan }\end{array}$ & $\begin{array}{c}11.205 .000(25 \\
\text { papan) }\end{array}$ & $\begin{array}{c}4.567(25 \\
\text { papan })\end{array}$ \\
\hline Kempa Dingin & $\begin{array}{c}27.000 .000(25 \\
\text { papan) }\end{array}$ & $\begin{array}{c}110.045 \\
(25 \\
\text { papan })\end{array}$ \\
\hline Kempa Panas & $\begin{array}{c}\mathbf{4 7 . 4 4 6 . 2 1 1 , 6 1} \\
\text { Joule }\end{array}$ & $\begin{array}{c}\text { Rp. } \\
\mathbf{1 2 5 . 7 5 0}\end{array}$ \\
\hline Total
\end{tabular}

Tabel 4 Data Hasil Perhitungan Energi

Dari tabel diatas dapat dilihat bahwasanya energi terbesar yang dibutuhkan berasal dari proses kempa panas dengan energi yang dibutuhkan sebesar 27.000.000 Joule untuk 25 papan, sedangkan energi yang paling kecil diterjadi pada proses pengadukan bahan yaitu sebesar 2.075 Joule. Energi yang dibutuhkan untuk membuat 1 papan adalah 47.446.211,61 Joule : $25=\mathbf{1 . 8 9 7 . 8 4 8 , 4 6}$ Joule.

Sedangkan biaya yang dibutuhkan untuk mencetak 25 papan partikel adalah sebesar Rp.125.750. Untuk biaya pembuatan 1 papan partikel adalah Rp.125.750 : $25=$ Rp.5.030

Harga buatan pabrik dengan ukuran $120 \mathrm{~cm} \mathrm{x}$ $250 \mathrm{~cm}$ dengan tebal $1,2 \mathrm{~cm}$ dengan harga Rp.90.000. Jika dibandingkan dengan harga per volume papan partikel, maka :

Papan partikel yang telah dibuat dengan ukuran $30 \mathrm{~cm}$ x $30 \mathrm{~cm}$ dan tebal $1,1 \mathrm{~cm}$ maka volumenya $=30 \mathrm{~cm} \times 30 \mathrm{~cm} \times 1,1 \mathrm{~cm}=990$ $\mathrm{cm}^{3}$, sehingga harga nya adalah

\section{$\frac{R p .5030}{990 \mathrm{~cm}^{3}}=5,08 \frac{R p}{\mathrm{~cm}^{3}}$}

Papan partikel buatan pabrik berukuran $120 \mathrm{~cm}$ x $250 \mathrm{~cm}$ dengan tebal $1,2 \mathrm{~cm}$, maka volumenya $=36.000 \mathrm{~cm}^{3}$, sehingga harga nya adalah

\section{$\frac{R p \cdot 90.000}{36.000 \mathrm{~cm}^{3}}=2.5 \frac{R p}{\mathrm{~cm}^{3}}$}

Dari perbandingan di atas harga per satuan voilume papan partikel buatan pabrik lebih murah dibandingkan dengan harga papan partikel yang telah dibuat. Hal ini terjadi karena proses pembuatan papan partikel di pabrik dilakukan dengan skala besar, sehingga menghemat waktu dan biaya proses pembuatannya, sedangkan papan partikel yang telah dibuat proses pembuatannya dilakukan dengan skala yang kecil sehingga terjadinya pemborosan waktu,energi dan tenaga.

(Sumber : http://hargaper.com/harga-triplekterbaru.com.html)

\section{PENUTUP \\ Simpulan}

Di dalam melakukan penelitian pembuatan papan partikel dengan serat tandan kosong kelapa sawit dan serbuk kulit kayu pinus dan akasia terhadap energi yang dibutuhkan dapat disimpulkan :

1. Energi atau Usaha terbesar yang dibutuhkan terjadi pada proses menggunakan mesin tetapi mempercepat pengerjaan. Sedangkan energi yang terkecildilakukan jika mengerjakansecara manual, hanya saja waktu yang dibutuhkan lama.

2. Konsumsi energy terbesar terjadi pada proses kempapanas yaitu sebesar 27.000.000 Joule, sedangkan energi paling kecil terjadi pada proses pengadukan bahan yaitu sebesar 2.075 Joule.

3. Biaya terbesar dalam proses pembuatan papanp artikel terjadi pada proses kempapanas, yaitu sebesarRp. 110.045 untuk 25 papanp artikel.

4. Jika dibandingkan dengan harga pasaran, harga papanp artikel yang telah dibuat harganya lebih mahal. Hal ini disebabkan karena proses pembuatan papanp artikel yang telah dibuat dilakukan dengan skala kecil, sedangkan papanp artikel yang dibuat di pabrik dilakukan dengan skala yang besar sehinnga menghemat waktu dan energi.

\section{Saran}

Saran atau masukan yang dapat saya berikan setelah melakukan penelitian ini adalah:

1. Dalam proses pengukusan serat TKKS harus menggunakan zat $\mathrm{NaOH}$ agar kandungan minyak pada serat TKKS dapat keluar saat dikukus.

2. Pengeringan serat TKKS yang telah dicuci dilakukan secara agar kandungan air pada serat TKKS hilang secara merata.

3. Proses pengadukan serat TKKS dengan serbuk kulit pinus atau akasiadi tambah denganbubuk UF dilakukakan secara merata agar tidak terbentuk gumpalan. 
4. Di dalam proses pembuatan sampel penelitian papan partikel serat tandan kosong kelapa sawit dan serbuk kulit kayu akasia agar mendapatkan hasil yang maksimal disarankan agar memperhatikan dalam proses kempapanas memasukkan serat kedalam cetakan pada proses kempa dingin dan kempapanas dan memperhatikan temperature dalam kempapanas agar dilakukan sesuai dengan literature dalam membuat sampel komposit papan serat.

5. Dalam proses pembuatan papanp artikel sebaiknya dilakukan dengan menggunakan mesin agar prosesnya lebih cepat serta dapat menghemat waktu pengerjaaan.

\section{DAFTAR PUSTAKA}

Fathanah, U., \& Sofyana. (2013). Pembuatan Papan Partikel (Particle Board) Dari Tandan Kosong Sawit Dengan Perekat Kulit Akasia Dan Gambir.

Ginting, E. U., Iswanto, A. H., \& Azhar, I. (2016). Menggunakan Campuran Perekat Uf Dan Pf Pada, 1, 51-57.

Muhdi., Risnasari, I., Dan Putri, L. A. P. (2013). Studi Pembuatan Papan Partikel.

Maloney. (1977). Produk-produk majemuk Papan Partikel n Papan Komposit.

Maloney, T.M. 1993. Mondren Particle Board And Dry Proses Fiberboard Manufacturing. Miller Fremann, Inc. San Fransisco.

Haygreen JG dan Bowyer JL. 1996. Hasil Hutan dan Ilmu Kayu : Suatu Pengantar. Sujipto, A.H,penerjemah; Yogyakarta: Gajah MadaUniversity Press. Terjemahan dari : ForestProduct and Wood Science: AnIntroduction.

Perkebunan, D. J. (2016). Kelapa sawit. Statistik perkebunan Indonesia komoditas kelapa sawit 2014-2016.

Puspita, R. (2008). Papan Partikel Tanpa Perekat Sintetis (Binderless Particle Board) Dari Limbah Industri Penggergajian.

Subiyakto, Prasetya, B. (2004) Pemanfaatan Langsung Serbuk Kulit Kayu Akasia sebagai Perekat Papan Partikel. UPT Balai Penelitian dan Pengembangan Biomaterial LIPI, Bogor.

Douglas C. 2001. Fisika Jilid I (Terjemahan). Jakarta : Penerbit Erlangga.
Halliday dan Resnick. 1991. Fisika Jilid I (Terjemahan). Jakarta : Penerbit Erlangga.

Tipler, P.A. 1998. Fisika untuk Sains dan Teknik - Jilid I (Terjemahan).Jakarta : Penebit Erlangga.

Young, Hugh D. \& Freedman, Roger A. 2002. Fisika Universitas (Terjemahan). Jakarta : Penerbit Erlangga.

https://id.wikipedia.org/wiki/Akasia. Diakses pada tanggal 1 Desember 2018.

https://en.wikipedia.org/wiki/Pine. Diakses pada tanggal 2 Desember 2018.

https://usaha321.net/perbedaan-usaha-danenergi.html. Diakses pada tanggal 12 Januari 2019.

https://artikel-teknologi.com/pengertianmaterial-komposit/. Diakses pada tanggal 13 Januari 2019.

http://haryobrono.blogspot.co.id/2010/11/mema nfaatkan-akasia-sebagai perekat.html. Diakses pada tanggal 13 Januari 2019

heatenergy-hotspot.weebly.com. Diakses pada tanggal 18 Januari 2019. 